Indexed by

\title{
Scopus
}

\section{EXTRACTION MECHANIZATION OF SOFT SOILS}

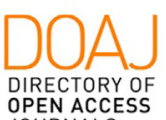

OPEN ACCESS

JOURNALS

\section{Polina Ivanova}

Crossref Saint Petersburg Mining University, Saint Petersburg, Russian Federation

\section{Sergey Ivanov}

Saint Petersburg Mining

University, Saint Petersburg,

Russian Federation

\author{
Aleksander Mikhailov \\ Saint Petersburg Mining \\ University, Saint Petersburg, \\ Russian Federation
}

KOBSON Dmitriy Shishlyannikov

Perm National Research Polytechnic University, Perm, Russian Federation

Key words: energy resources, local fuel, peat raw materials, undrained deposits, mining bucket, from under water, aggregated complex

doi:10.5937/jaes0-31904

\section{Cite article:}

Ivanova, P., Ivanov, S., Mikhailov, A., Shishlyannikov, D. (2021) EXTRACTION MECHANIZATION OF SOFT SOILS, Journal of Applied Engineering Science, 19(3), 610-617, DOI:10.5937/ jaes0-31904

Online aceess of full paper is available at: www.engineeringscience.rs/browse-issues 


\title{
EXTRACTION MECHANIZATION OF SOFT SOILS
}

\author{
Polina Ivanova ${ }^{1 *}$, Sergey Ivanov', Aleksander Mikhailov', Dmitriy Shishlyannikov ${ }^{2}$ \\ ${ }^{1}$ Saint Petersburg Mining University, Saint Petersburg, Russian Federation \\ ${ }^{2}$ Perm National Research Polytechnic University, Perm, Russian Federation
}

The state economic development is largely determined by the effectiveness of its individual structural elements. Among them, a special place is occupied by trends in the mineral sector, which dictates the requirements and mechanisms for the development of natural resources, creating the basis for a national strategy. However in this area there are a number of unsolved problems, which include: a low level of rational use of machine-technological mining systems from under the water with minimal man-made impact. The authors consider existing and alternative extraction methods of peat raw materials. The tasks facing the mineral re-source sector can be solved through technological priority developments of aggregated extraction complexes for the peat raw materials and the equipment modernization for mining complexes. The analysis is carried out and recommendations are made for the working equipment modernization of the aggregated mining complex. Variants of the excavator excavation bucket for the extraction of peat raw materials from under water have been proposed. The results of studies on primary dehydration, combining mining and dewatering cycles in a bucket, are presented; the work gives the recommendations on the bucket use and the expediency of op-erating the mining machine's extraction body when extracting peat raw materials.

Key words: energy resources, local fuel, peat raw materials, undrained deposits, mining bucket, from under water, aggregated complex

\section{INTRODUCTION}

Resource development within the framework of the mineral resources sector of many countries is an integral part of their development. However, it is the extractive industry that has a negative impact on the ter-ritory where this production is carried out, and contributes to an increase in economic risks. At the same time, soft soils are characterized by high deformation and low permeability. To date, a significant part of the Russian Federation territories is represented by weak soils, which include bog soils, silts, peat of various origins. Such soils, as a rule, are waterlogged and are in a fluid-plastic state. Some of the fields are known to be flooded, and their development is difficult, which requires significant additional costs and the use of innovative technical and technological solutions. The task becomes even more complicated when extracting renewable fuel resources, which include raw peat. At the same time, a promising method for extracting peat raw materials from a flooded deposit is open-pit mining with mineral excavation for the entire thickness of the reservoir from a pontoon, which requires the use of special attach-ments to implement this technology.

\section{MATERIALS AND METHODS}

\section{Theoretical treatment}

As the world experience shows within the framework of the reasonable use of energy raw materials, peat deposits are increasingly involved in the economic turnover, as a component of a small energy cluster, and the improvement of development technology, the use of new equipment and technologies using the best available technologies (BAT) within the framework of climate neu- tral economic activities. [1, 2, 3, 4].

The total area of peats in the world is estimated at 500 million hectares. The most intensive peat accumulation is typical for the Nordic countries, the Russian Federation, the USA and Canada. [5-6, 7-9].

At the same time, domestic reserves account for about $47 \%$ of the world, while the annual growth of peat is more than 60 million tons per year. The use relevance of peat raw materials in the fuel and energy sector of the Russian Federation is determined by its priority compared to long-range fuels such as coal, oil, fuel oil, and is second only to natural gas. Peat is a local type of fuel, environmentally friendly resources, relatively evenly distributed in geography, while in the process of its combustion, sulfur dioxide is emitted into the atmosphere 50 times less than from burning fuel oil or coal [10].

The order implementation of the Russian Federation Government of June 9, 2020 No. 1523-r "On the Energy Strategy of the Russian Federation for the period up to 2035" involves the introduction of new gen-erating capacities operating on non-traditional renewable energy sources, which include peat [1, 11]. In the energy cluster peat raw materials are a promising source of heat and electrical energy. So, for example, for the production of various products in agriculture, in the chemical industry and medicine, only peat raw mate-rials of a certain composition and quality can be used, then practically all types of peat are applicable for energy potential. The increased interest in this type of fuel is due to a decrease in transportation costs as a local type of fuel in comparison with other energy resources. However, being in wet- 
lands, the extraction of peat raw materials requires special equipment and technologies to ensure its efficient extraction. Many technologies are associated with the need for dewatering of territories, which does not agree well with climate-saving technologies. The alternative in this case is the extraction of peat raw materials from the deposit surface without draining it, directly from under the water.

When excavating from under water, there is a steady downward trend in the excavator performance due to increased losses of mineral resources, which is associated with the loss of visual control over the bucket interaction with the bottom, washing out of the mineral from the bucket when it moves under water and carrying away part of the peat raw materials along with the liquid when lifting the bucket above the water cut.

The aim of the work is to identify promising directions for the development of mining equipment and increase the efficiency of its functioning in the extraction of peat raw materials in undrained deposits within the framework of the innovative circuit solution formation for the structural-parametric synthesis of aggregated fuel and energy complexes capable of extracting and processing peat raw materials within the framework of environmentally friendly resource-saving technologies that ensure high profitability of production.

In order to achieve this goal, it is necessary to solve a number of tasks: to analyze and give proposals for rationalizing the existing methods of extracting raw peat; develop proposals for improving the working equipment of the complex, interconnecting the aggregated elements of the complex with each other in the production-processing system; to assess the prospects for the application of new circuit solutions, to conduct research on the most energy-intensive process - excavating peat raw materials from under water.

\section{Methodological background}

The processes associated with the extraction, production and processing of peat raw materials are complex physical, technological and chemical, based on the scientific foundations of the mechanics physics, taking into account the peculiarities of structural changes in wet inhomogeneous materials during their mechanical destruction, deformation and dehydration [12].

The latter are due to the significant water content $(\omega=$ $92-96 \%$ ) in the natural state. Moreover, the re-moval of moisture is associated with the optimization of enrichment and structure formation processes in peat production technology, which actively change the properties of the solid phase (strength Ri, density vi, crumbling, moisture content $W$, resistance to external influences, etc.), as well as the development and sub-sequent use of machines and aggregates [12]. Taking into account the variety of peat extraction methods such as: milling, scraper-bulldozer, milling and elevator, until recently, the most common milling method for extracting peat raw ma- terials, which is layer-by-layer milling of peat, previously drained and prepared deposits with subsequent field drying and cleaning $[13,14]$. The scraper-bulldozer method of extraction is a layer-by-layer loosening of the peat deposit surface with the formation of a spread of peat chips, field drying and its harvesting. The milling method for the extraction of sod peat involves slotted or layer-by-layer milling of peat deposits, shaping peat raw materials in the form of lumps, their field drying and harvesting. These methods require the use of large areas and their preparation, which in modern economic conditions is becoming less and less attractive [14].

The excavator method of extracting peat raw materials is largely devoid of these drawbacks and ensures production in limited areas for the entire capacity of the deposit. However, as mentioned above, all of the methods for peat extraction require preliminary preparation of deposits and the implementation of a set of works on their dewatering for the use of large-capacity equipment at the stages of extraction, molding and drying.

Since many peat deposits are largely watered, the technology of mining such minerals can be implemented using excavator and hydro mechanized methods of their development [16, 18].

However, new times also dictate new requirements - the use of the best available technologies that minimize environmental risks of negative situations, preserve natural areas near the developed deposits, reduce anthropogenic impact on the environment - all this is impossible without the development of new inno-vative mining equipment.

Any functioning element (of a mining machine/mining equipment) builds up on its mechanical part and a drive (electric, hydroelectric, or sometimes ICR). Drive transfers power to an actuating element and transmission. Here, combined structural formula of a common functioning element $\left(\mathrm{FUN}_{\mathrm{i}}\right)$ will be:

$F U N_{i}=\left(\left(\left(M_{i}+F g_{i}\right)+F e_{i}\right) I_{i} \cdot E_{i}\right)_{i}$

where $M_{i}$ is a mechanical part, or mechanic transmission of an actuating element; $F g_{i}$ is for a hydraulic transmission and a hydraulic drive; $F e_{i}$ is an electric drive; $E_{i}$ is an electronic element that forms, transmits, and processes electric signals; $I_{i}$ is form information element that forms, transmits, stores, and processes information signals.

Two last components are a management and feedback element $\left(E_{i}\right)$ and information flows $\left(I_{i}\right)$ transmitted from transducers. These components monitor status and functioning of the elements that comprise the automation system.

In our case, expanded structural formula for excavating mining machine or the corresponding functioning element will be:

$F U N_{D B}=\left(\left(M_{D B}+F g_{N 1}+F e_{N}\right)+\left(M_{T}+F e_{T}\right)\right)+I_{D B} E_{D B}$

It is worth mentioning that discrete parameters and sizes of current mining machines cannot allow aggregated 
mining complexes to be built up with such machines. It is hard to combine energy consumption, weight and other technical parameters of the functioning elements that comprise a mining complex into a single system against the backdrop of parametric synthesis. To resolve this complicated task, it seems to be reasonable to perform numerical studies that would consolidate corresponding parameters of the mining equipment and determine functional relations between functioning elements of adjusted mass and power and their performance score. The above mentioned analysis included hydraulic excavators from various producers Komatsu, CAT, Hitachi, Volvo, TVEXC of various sizes that resulted in determining the dependency of performance $Q_{E}$ on power $N_{E}$ and mass $m_{E}$ :

$N_{E}\left(Q_{E}\right)=37,9 e^{0,02 Q_{E}} ; R^{2}=0,78$

$m_{E}\left(Q_{E}\right)=7,7 e^{0,02 Q_{E}} ; R^{2}=0,75$

High determination coefficient $R^{2}$ proves that the numerical experiment led to the determination of factor-regressive dependencies.

Graphical representation of the functions in nomogram allows us to get a tool for a quick and motivated choice of main parameters for such equipment. Utilizing this method, it is possible to retrieve not only aggregated data for a whole machine but also to get data on its elements [13].

\section{Development problems of water-bearing deposits}

For the mining industry of the Russian Federation, the urgent task is to develop watered mineral depos-its, which is included in the list of critical technologies of the Russian Federation and requires its solution.

Most of the enterprises developing flooded mineral deposits incur significant costs for mining operations and creating conditions for their effective implementation. The share of these costs in the production cost can reach up to $30-40 \%$. At the same time a global problem that requires its solution is the negative impact and violation of the biosphere balance of the area, the risk of fires. The introduction of new, environmentally balanced, resource-saving and hydro-mechanized technologies for the development of water-flooded fields within the framework of the strategic development of science and technology makes it possible to significantly change the approaches to the production of energy fuel based on peat. Peat deposits, being labile natural ecosystems, require a special approach to their development and balanced science-intensive technologies for the extraction and production of peat fuel [19]. The most important principle of the rational use of natural resources is a harmonious combination for the economic development tasks of peat mining enterprises and environmental protection. A radical method of overcoming the contradictions between these tasks is the transition to environmentally friendly technologies that exclude or reduce environmental risks in their application.
It should also be considered that for the preparation of such deposits, including peat deposits, their development implies the efficient operation of high cross-country machines. In order to ensure this condition in the development of undrained deposits, it is possible to use mining equipment with its installation relative to the bottom in the form of a surface, flood and underwater location. The use of the latter for peat bogs is not advisable, the above-water arrangement of equipment requires the use of bridge structures, for the movement of which, it is also required to build reliable routes, as for the flooding of equipment, this option seems to be the most preferable. Above-ground mining equipment in the development of undrained peat deposits is pos-sible to use tracked excavators installed on a pontoon, pontoon excavators and dredgers (dredges).

The floating placement of excavators on a pontoon is effective in watered fields, since it excludes the drainage process of the quarry space, can significantly reduce the cost of the extracted mineral, and also helps to reduce the total energy consumption of the mining enterprise.

Taking into account the different location of the fields and, as a consequence, the transport inaccessibil-ity for the preparatory work implementation in the extraction and further transportation of the extracted raw materials, a distinctive feature of new machines and complexes should be the versatility of buoyancy and self-propelled power, at the same time, energy efficiency and the ability to operate year-round [20]. In order to meet these requirements, it is necessary to aggregate machines into a single complex, for example, in the form of a self-propelled floating platform with autonomous power generation and interconnected mining equipment, through which the extraction, processing and transportation of peat raw materials is carried out in a single flow cycle.

The lack of specialized equipment in domestic quarries, designed for the development of underwater faces, leads to an increase in the cost of mining operations and tangible losses of mineral raw materials.

When forming new complexes for the extraction and processing of peat raw materials, one should also take into account such factors as the continuity of material and energy flows. In the conditions of undrained peat deposits, the use of basic machines will be inappropriate, since it is necessary to coordinate the performance of the mining machines used in the form of appropriate modules along the entire chain of the complex equipment to ensure the continuity of the movement of material flows. Thus, it is not possible to use equipment of standard size series and it is required to create units (modules) of mining equipment of the complex with technical characteristics that are interrelated with each other and, first of all, in terms of their productivity. Also, in order to minimize the number of working elements on the platform, it is proposed to combine individual elements into a single whole. So, for example, peat dehydration in the executive body of the mining machine will be rational. 


\section{RESULTS}

\section{Analysis and features of buckets for the peat raw materials extraction in water-bearing deposit}

This type of mineral is specific, so a non-standard bucket must be used for its extraction. Unlike bulk materials, such as gravel, sand, in which moisture is in an unbound state and can leave through internal channels, in peat raw materials only part of the moisture is in a free state and a few channels easily overlap when the peat raw materials are deformed, thus, when squeezing raw materials moisture reduction is carried out only on the surface in a thin layer. The high moisture content of the peat deposit, its natural stumpiness, makes the standard excavation process less efficient with a typical bucket [22].

To date, increasing the productivity of mining equipment is an urgent task. In general, to solve this problem, various operational control systems are used, another direction in solving this problem can be constructive changes in order to simplify the introduction of the working body into the material and increase the volume of scooped up soil.

A possible solution would be to upgrade the excavator excavation bucket. Namely: increasing the efficiency of extraction of peat raw materials by creating drain holes, cutting edges and taking into account the method of extraction of peat raw materials.

In order to conduct a qualitative analysis of the efficiency of the extraction of peat raw materials by the working body of an excavator, it is first of all necessary to determine the factors that have the greatest influence on this process. These factors include:

1. Geometrical parameters of the working body of the earth-moving machine;

2. Operation modes of the working body in the earth-moving machine;

3. The design of the working body in the earth-moving machine;

4. Physical and mechanical properties of peat in the deposit;

5. Availability of open water during extraction from under water;

6. The level of disturbance of the extracted raw materials. The efficiency degree of the mining process directly depends on the size and design features of the working bodies of mining machines. So, for example, when carrying out the extraction of peat raw materials by an excavator method, special attention is paid to the execution of the working equipment, in particular, the design parameters of the bucket. To date, manufacturers produce a wide variety of models and modifi-cations of buckets for mining from under water. The so-called troughs [23], shown in Figure 1.

\section{Figures, Tables and Scheme}

All figures and tables should be cited in the main text as Figure 1, Table 1, etc.
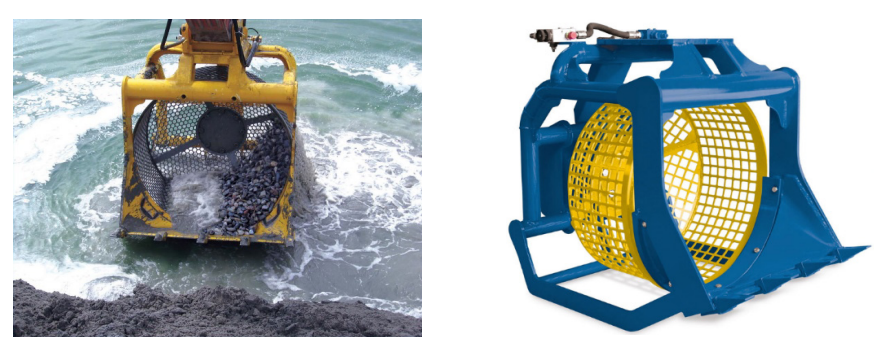

Figure 1: Thoughs [24]

The washing bucket-sorter is designed for cleaning soil from solid impurities, secondary sorting of waste and at the same time drainage. The drum of the sorter is made of wear-resistant material, which guarantees the durability of the device. Such buckets have found their application for the extraction of building materials, but the use of this bucket for peat soils is problematic, due to significant losses of raw materials leaving with water.

For soft soils, digging grabs have proven themselves well (Figure 2) [23].

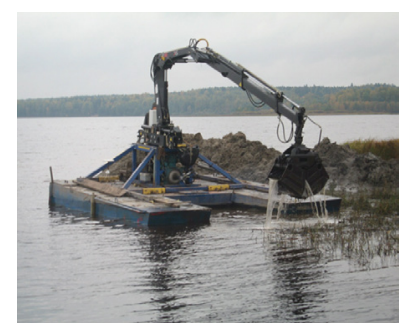

Figure 2: Grab [25]

Their great advantage is the fact that they are able to handle vertical faces and ensure the safety of the material when moving under water, but peat raw materials excavated in this way require additional crushing.

Skeleton buckets (Figure 3), which are also called lattice or screening, drainage buckets, like other types of this technique, present by their names. They are indispensable when you need to load stones or divide them into separate fractions. Due to the design features and the presence of a grate, large particles can be removed from the soil, while sifting out small fractions [23].
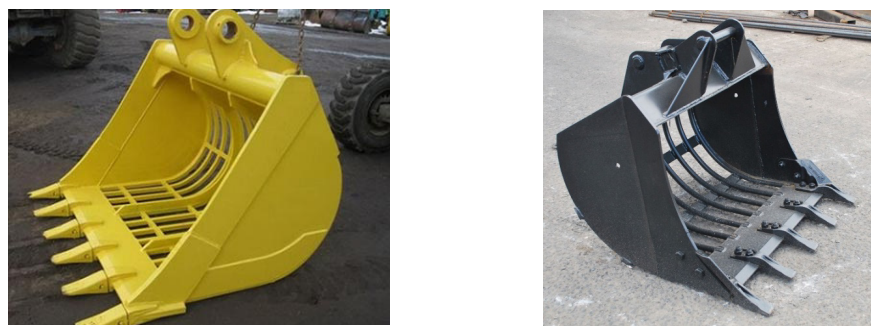

Figure 3: Drainage buckets

The use of such buckets for the extraction of peat raw materials is ineffective due to significant losses of raw materials during digging and transportation. This type of ladle will be useful in the development of deposits with wood inclusions, the extraction of which is necessary for further efficient mining of minerals. 
Excavator stripping and leveling buckets (Figure 4) refer to attachments that are used when digging bypass drainage canals, cleaning water bodies, river beds from wood, plant sediments and various trashes, and when leveling surfaces [23].
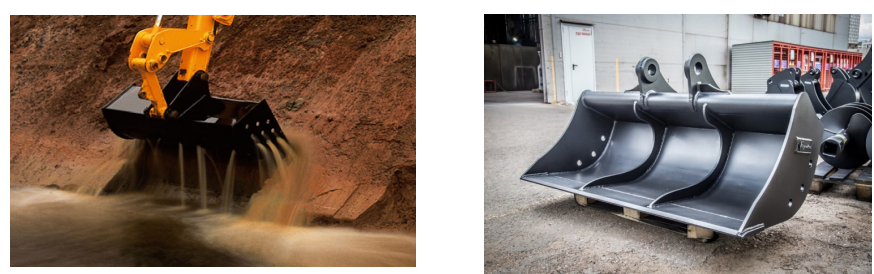

Figure 4: A trimming bucket and a slope bucket

With regard to the process of extracting peat in undrained deposits, buckets are widely used, a distinctive feature of which is the presence of perforations in the bottom, as well as on the side walls in order to effectively empty the bucket from excess moisture; for watered operating conditions, holes for drainage are provided in their bottoms and side faces water [26, 27] (Figure 5).

Based on the practical experience of underwater excavation using draglines, during the development of rocks of the I - III category of fortress (according to UCRFuniform classification of rock formation), a decrease in excavator productivity by $15-20 \%$ appears. During underwater excavation in water-bearing deposit, the digging process becomes difficult due to the impossibility of visual control of the face surface and, as a result, the bucket filling factor decreases and the excavator's operating cycle increases [23].

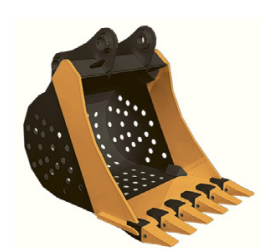

Figure 5: Modification of the drainage bucket with perforated walls and bottom
Despite the external design variety of excavator executive bodies and their various applications depending on operating conditions, they have much in common in terms of design and principle of operation. As the practice of using loading machines shows, most of them work with incomplete filling of the bucket and, thus, the technical performance is significantly lower than the calculated one. So, a significant influence on the filling of the ladle is exerted by its kinematics during the digging process.

Also, the degree of filling the bucket, on the one hand, is influenced by the mining and geological conditions and properties of materials, on the other, by the geometric parameters of the working body used and the corresponding efforts.

The main relationships that take place when digging various rocks are shown in Figure 6 . The work demonstrates dependences of the bucket penetration efforts on the penetration depth of the bucket bottom into the rock layer.

Experimental studies have shown that the geometric parameters and structural elements of the working body in the process of digging have a significant impact on the force value of penetration into the rock. It has been established that when the bucket is introduced, the leading edge of the bottom must move directly over the top soil layer. If the edge penetration is at a certain distance from the soil, then due to the formation of the leading edge of a large drag prism, the penetration efforts increase by about $30-50 \%$, especially this tendency is observed when developing coarse rocks. It was also found that when the geometrical parameters of the bucket change, the forces increase in proportion to the bucket width.

Based on the data mentioned above, it can be concluded that it is advisable to take into account the influencing factors on the efforts of introducing the bucket. In order to take into account all factors influenc-ing the implementation effort, the following empirical relationship is proposed:

$$
P_{\text {in }}=c \cdot k_{h} \cdot k_{f} \cdot p_{0} \cdot B
$$

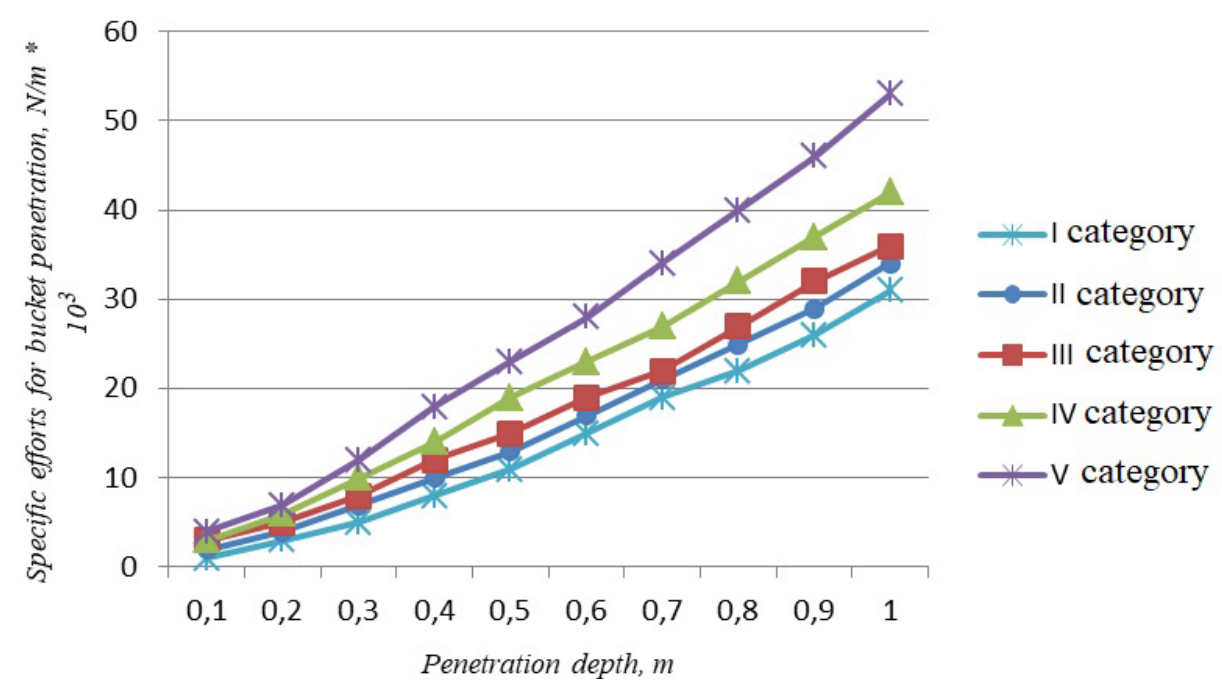

Figure 6: Dependence of specific efforts for bucket penetration on penetration depth for different rocks by excavation difficulty 
where $c$ is the coefficient taking into account the properties of the rock; $k_{h}$ is a coefficient that takes into account the effect of the layer height; $k_{f}$ - coefficient taking into account the geometrical parameters of the bucket; $p_{0}$ - specific force of bucket penetration at the selected penetration depth, $\mathrm{N} / \mathrm{m} ; B$ - bucket width, $\mathrm{m}$.

Working in undrained deposit requires preliminary soil dewatering by the use of perforated buckets with various perforation square $(S)$. An experiment with a physical model (perforation $R_{v} 2-8$, perforation square $32 \%$ ) was performed. As a soil model, there was excavated peat cut in pieces that imitated peat shavings. This material was divided into three parts where the material from the second part was consolidated, while the material from the third part was highly consolidated. Base moisture content level was the same in all three groups of materials equal to $89 \%$.

During the experiment, the model filled with peat material with its mass monitored by three weighing. Peat material was exposed to the pressure of $0.02 \mathrm{MPa}$ applied to the puncheon by a load weight for $30 \mathrm{sec}$. After 30 seconds passed, the expressed peat material was weighed.

Based on the experiment results, approximation showed changing of moisture content in peat material resulted from extrusion. The extent of change depended on the bucket perforation square and the extent of material consolidation. Regressive formulae $m=A \exp (b S)$ had high determination coefficients $R^{2}=0,78-0,88$. Research showed that increase in perforation square $(S)$ increases the volume of expressed moisture, but the intensity of extrusion allowed us to conclude that moisture removal takes place only in the outer layers of the material that are the closest to the perforated surface. Central part of the material preserves the same level of moisture content as the initial one. The greatest moisture removal effect is achieved when non-consolidated material is extruded. Such material has the channels for water to flow from the center to the outer layers of peat material sample [30-33].

Normally, this material presents in the bucket during peat shavings excavation from the separated peat material. For the first case, regressive formula for non-consolidated peat material was:

$m=8,4 \exp (0,007 S)$

In order to intensify moisture separation during the extraction of peat raw materials, it is proposed to combine the operation of preliminary dehydration of the material in the ladle itself; this implementation is possible by installing an additional pressing wall (Figure 7).

In the depths, the sample practically does not change its moisture. In this case, the greatest effect of water distribution takes place in the case of squeezing out non-compacted material, when there are channels for the squeezed moisture passage from the depth to the outer surface, which takes place when filling the bucket with shavings cut off at the bottom of the peat raw material.

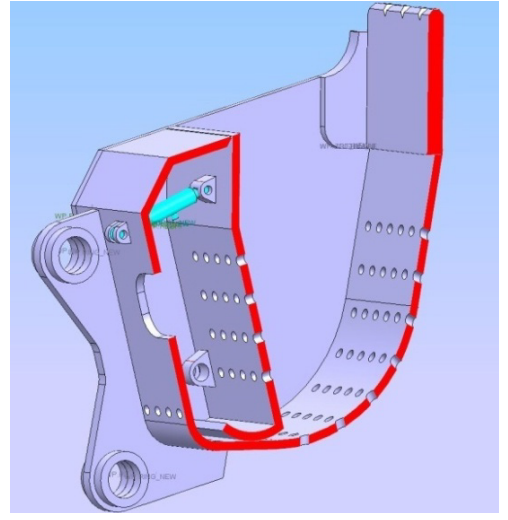

Figure 7: Proposed bucket design with perforation and press wall

\section{DISCUSSION}

Thus, based on the analysis of primary mechanical dehydration in the excavator's executive body, it is confirmed that it is possible to reduce the moisture content directly in the bucket of unconsolidated peat raw materials, with an increase in compaction with further processing, the decrease in moisture in peat by mechanical squeezing becomes more and more difficult [29; 34]. During excavation, it is possible to achieve the required structure of the extracted material only when the cutting edge of the bucket removes relatively thin chips, for this purpose it is necessary to modernize the bucket, which is the task of further research.

\section{CONCLUSIONS}

Equipment designed for the development of water-bearing deposit, except for dredgers and dredges, is not produced in Russia and, using it, in many cases does not allow working out the water-bearing strata to the full depth. The lack of specialized equipment leads to a rise in the cost of mining and tangible losses of mineral raw materials.

Summarizing the stated data and confirming the actualization of research on the extraction of minerals from under water, which is a rather difficult task for the mineral sector of many countries, as well as the lack of specialized equipment and the shortcomings of existing methods for extracting peat raw materials from undrained deposits, we can conclude that in the modern world requires special attention from the state, aimed at the development and implementation of promising and efficient mining complexes of the energy cluster, which allow realizing the extraction of peat without drainage of territories with minimization of neg-ative consequences for the environment.

\section{REFERENCES}

1. Inisheva, L.I. The concept of protection and rational use of peat bogs in Russia. Under total. ed. Corre-sponding member RAAS, 2005. pp. 74-97 [In Russian] 
2. Zarovnyaev, B.N.; Popov, V.F.; Shubin, G.V.; Budikina, M.E.; Sokolova, M.D. Development of peat deposits in the arctic and subarctic regions of Russia. Mining information and analytical bulletin (scientific and technical journal), 2020, Vol. 6, pp. 168-177 [In Russian] DOI: 10.25018/0236-1493-2020-6-0-168-177

3. Derevyashkin, I.V.; Sadykov, A.A. Scientific substantiation of the method of industrial extraction of amber, preventing its crushing in the face. Mining information and analytical bulletin, 2019, no. 11, pp. 81-93. [In Russian] DOI: 10.25018 / 0236-14932019-11-0-81-93.

4. Jean de Dieu; Hakizimana, K.; Hyung-Taek Kim. Peat briquette as an alternative to cooking fuel: $A$ techno-economic viability assessment in Rwanda. Energy, 2016, Vol. 102, pp. 453-464.

5. Heikkinen, K.; Karppinen, A.; Karjalainen, S.; Postila, H.; Hadzic, M.; Tolkkinen, M.; Marttila, H.; Ih-me, R.; Kløve, B. Long-term purifcation effciency and factors affecting performance inpeatland-based treatment wetlands: An analysis of 28 peat extraction sites in Finland. Ecological Engineering, 2018, Vol. 117, pp. 153-164.

6. Rieli, J.; Silpola, J.; Warnecke, S. World Energy Resources: Peat, Finland. 2013, pp. 1-24. Available online: https://www.worldenergy.org/wp-content/uploads/2013/10/WER_2013_6_Peat.pdf [Electronic resource] (date accessed: 09.09.2020).

7. Litvinenko, V. S. Digital economy as a factor in the technological development of the mineral sector. Natural Resources Research, 2019, Vol. 28, no. 28, pp. 1-21.

8. Litvinenko, V. S.; Sergeev, I. B. Innovations as a Factor in the Development of the Natural Resources Sector. Studies on Russian Economic Development, 2019, Vol. 30, no. 6, pp. 637-645.

9. Tcvetkov, P.S. The history, present status and future prospects of the Russian fuel peat industry. Mires and Peat, 2017. Vol. 19, no. 14, p. 1-12.

10. Rostorf. The use of peat as a strategic resource of Russia in the interests of a diversified economy. Available online: http://rostorf.ru/files/all.pdf (date of access: 09/09/2020).

11. Energy strategy of Russia for the period up to 2030. Approved by the order of the Government of the Russian Federation of November 13, 2009, no. 1715, p. 144.

12. Shtin, S.M. The use of peat as a fuel for small-scale power generation. Mining information and analytical bulletin (scientific and technical journal), 2011, no. 8, pp. 82-96.
13. Khudyakova, I.N.; Vagapova, E.A.; Ivanov, S.L. Choice and justification of parameters of technologi-cal equipment for the complex of peat raw material extraction from natural deposits, Gorny infor-matsionno-analiticheskiy bulletin, 2019, no. 3 (special issue 4). - pp. 3-15.

14. Gamayunov, S.N. On the issue of classification of methods of peat extraction. Proceedings of Instorf, 2014, Vol. 81, no. 3, pp. 145-150.

15. Cherepovitsyn, A.E.; Tsvetkov, P.S. Methodical Approach to Evaluation of the Russian Peat Deposits Exploitation Attractiveness Based on Geology-Technological Criteria. International Journal of Applied Engineering Research, 2016, Vol. 11, no 7. pp. 5072-5078.

16. Kremcheev, E. A. Special features of a structure of technical operations for peat excavation with stage dewatering. Journal of Mining Institute, 2018, Vol. 231, pp. 225-234.

17. Gharedaghloo B., Price J. S., Rezanezhad F. and Quinton W. Evaluating the hydraulic and transport properties of peat soil using pore network modeling and X-ray micro computed tomography, Journal of Hydrology, 2018, Vol.561, pp. 494-508. 10.1016/j. jhydrol.2018.04.007

18. Kremcheev, E. A.; Nagornov, D. O. Features of structure of process operations set during peat excava-tion with staged dehydration. Ecology, Environment and Conservation, 2017, Vol. 2, no. 23, pp. 956 - 965.

19. Mikhailov, A.V.; Kremcheev, E.A.; Bolshunov, A.V.; Nagornov, D.O. Prospects for the development of new technologies for peat extraction. Mining information and analytical bulletin (scientific and technical journal), 2010, no. 9, pp. 189-194.

20. Ivanov, S.L.; Ivanova, P.V.; Kuvshinkin S.Yu. Estimation of operating time of open pit excavators of a promising model range in real operating conditions. Journal of Mining Institute, 2020. Vol.242. pp. 228233. DOI: 10.31897 / PMI.2020.2.228

21. Talgamer, B.L.; Semenov, M.E. Assessment of the quality of underwater excavation of minerals. Mining information and analytical bulletin, 2017, no. 1, pp. 350-356.

22. Production and repair of special equipment and attachments. Available online: http://zavodkovshey. rf/kovsh-proseivayushchiy (date of access: 09/09/2020). 
23. Klementyeva, I.N.; Kuziev D.A. Excavation and loading dragline with a bucket of innovative design. Mining information and analytical bulletin, 2019, no. 7, pp. 149-157. DOI: 10.25018 / 0236-1493-2019-070-149-157.

24. Bucket-sorter. Available online: https://www.tehno-group.com/ru/hinged_equipment/k_po_firmam/ romea/sortirovka (date of access: 09/09/2020).

25. Dredging operations. Available online :https://g-continent.ru/vidy-rabot/dnouglublenie (date of access: 09/09/2020).

26. Kononenko, E.A.; Sadykov, A.A. Hydro mechanized technology at the quarry of the Kaliningrad amber plant. Mining information and analytical bulletin, 2015, no. 11, pp. 105-113.

27. Menegaki M., Michalakopoulos T. and Roumpos C. Exploring the effect of physical, human and technical factors on bucket wheel excavators' efficiency: a fuzzy cognitive map approach, International Journal of Mining and Mineral Engineering. 2019. 10(24), pp. 189-204. DOI:10.1504/IJMME.2019.104447.

28. Samson-Dô, M., St-Hilaire, A. Characterizing and modelling the trapping efficiency of sedimentation basins downstream of harvested peat bog. Canadian Journal of Civil Engineering, 45, pp. 478-488, 2018. DOI:10.1139/cjce2017-0330.

29. Khudyakova, I.N.; Vagapova, E.A.; Ivanova, P.V.; Ivanov, S.L. Modeling the process of mechanical dehydration of peat raw materials in the working bodies of mining machines. Journal of Physics: Con-ference Series, 2020, Vol. 1753 012048, pp. 290-296. DOI:10.1088/1742-6596/1753/1/012048

30. Yemelyanov, V. A., Yemelyanova, N. Y., Shved, E. V., Nedelkin, A. A., \& Rubak, E. O. (2020). Ob-ject-oriented design of the specialized software for automation of the metallographic analysis. Paper presented at the Proceedings of the 2020 IEEE Conference of Russian Young Researchers in Electrical and Electronic Engineering, ElConRus 2020, 556-559. doi:10.1109/EIConRus49466.2020.9039284
31. Pimnev, A. L., Zemenkova, M. Y., Zemenkov, Y. D., \& Iljyashchenko, D. P. (2016). Mechanical prop-erties of the assembly welded joint of the oil transportation tank after a long-term service. Paper pre-sented at the IOP Conference Series: Materials Science and Engineering, 127(1) doi:10.1088/1757899X/127/1/012049

32. Mustafin, A. (2006). Two mutually loss-coupled lasers featuring astable multivibrator. Physica D: Non-linear Phenomena, 218(2), 167-176. doi:10.1016/j. physd.2006.05.003

33. Galevskiy, G. V., Rudneva, V. V., Galevskiy, S. G., II'Yashchenko, D. P., \& Kartsev, D. S. (2016). Nanosized borides and carbides for electroplating. metal-matrix coatings: Specifications, performance evaluation. Paper presented at the IOP Conference Series: Materials Science and Engineering, 125(1) doi:10.1088/1757-899X/125/1/012032

34. Zhukovskyy, V., Zhukovska, N., Vlasyuk, A., \& Safonyk, A. (2019). Method of forensic analysis for compromising carrier-lock algorithm on 36 modem firmware. Paper presented at the 2019 IEEE 2nd Ukraine Conference on Electrical and Computer Engineering, UKRCON 2019 - Proceedings, 11791182. doi:10.1109/UKRCON.2019.8879941 